\title{
Vaginal Progesterone versus Cerclage for Preventing Preterm Birth in Asymptomatic Singleton Pregnant Women with a History of Preterm Birth
}

\author{
MOHAMED A. ABD AL-AZIZ, M.Sc.; FAHD A. EL OMDA, M.D. and AHMED T. ABD EL FATTAH, M.D. \\ The Department Obstetrics and Gynecology, Faculty of Medicine, Al-Azhar University
}

\begin{abstract}
Background: Preterm birth is a hazard for deleterious short and long-term health outcomes. Cerclage is not a fit for all clinical situations Progesterone clearly plays a role in the maintenance of pregnancy through the relaxant effect of progesterone on myometrial strips in vitro. The progesterone usage in the prevention of preterm birth (PTB) in both singleton and multiple pregnancies has been broadly investigated.
\end{abstract}

Aim of Study: Was to compare the efficacy of vaginal progesterone and cerclage in preventing preterm birth.

Patients and Methods: This randomized prospective study was conducted at Al-Hussien University Hospital and Kafr El-Sheikh General Hospital during the period from May 2018 to September 2021. A total 150 pregnant women at high risk of preterm birth who were chosen from the outpatient clinics. They all had singleton pregnancy with gestational age at the first antenatal visit of 12-16 weeks. Additionally, they had history of previous spontaneous preterm labor, and they all presented with sonographic cervical length $<25 \mathrm{~mm}$ in mid trimester.

Results: It was observed that in cases who received vaginal progesterone in vaginal progesterone the mean gestational age was $(35.68 \pm 2.63$ weeks) while it was $(36.14 \pm 2.11$ weeks $)$ in those who underwent cerclage. The mean gestational age improved in the cerclage groups by about 3.92 days. The gestational age at delivery was higher in the cerclage group than that in the progesterone group, but without significant difference ( $p=0.239)$. There was statistically significant difference between the both studied groups regarding mean birth weight as it was $2185.9 \pm 314.2$ in women who received vaginal progesterone compared to $2305.8 \pm 234$.6 in women who underwent cerclage; with $p=$ value $=0.025$ ) this may be due to higher percentage of term pregnancy in cerclage group than progesterone one. The mean Apgar score at 1 minute was higher in the cerclage group than that in the progesterone groups (7.79 vs. 7.72). This results showed that the di erence in the mean Apgar score was not statistically significant between the progesterone and the cerclage groups $(p=0.809)$

Correspondence to: Dr. Mohamed A. Abd Al-Aziz, E-Mail: dr.mohamedalsayed17@gmail.com
Conclusion: Either vaginal progesterone or cervical cerclage had a significant beneficial effect in the protection against preterm delivery and improving perinatal outcomes among high risk women with a singleton gestation, previous spontaneous preterm birth or a mid trimester sonographic short cervix.

Key Words: Vaginal progesterone - Cerclagefor preventing preterm birth - Pregnant women.

\section{Introduction}

PRETERM birth remains the major cause of handicaps among children without congenital anomalies, however, the prevention has been largely unsuccessful due to the multifactorial etiology and effective preventative Strategies are required to minimize the burden of prematurity [1]. The incidence of preterm births is increasing in many countries around the world and has become a global health concern and anticipated to increase steeply over the next decade [2].

Although the rate of preterm birth has risen, some interventions have been demonstrated to have a potential role in reducing the likelihood of recurrent preterm birth in women with prior preterm births [3]. It is widely accepted that preterm birth is a syndrome caused by several pathological processes such as infection, vascular and decidual disorders, uterine over distension, breakdown of maternal-fetal tolerance, a decline in progesterone action, and cervical disease [4] .

A previous spontaneous preterm birth is a wellknown risk factor for recurrent spontaneous preterm delivery. A recent meta-analysis reported that the overall risk of recurrent spontaneous preterm birth $<37$ weeks of gestation was $30 \%$. A short cervix, conventionally defined as a transvaginal sonographic cervical length $\leq 25 \mathrm{~mm}$ in the midtrimester 
of pregnancy, is also an important risk factor for spontaneous preterm delivery and has emerged as one of the strongest and most consistent predictors of preterm birth in asymptomatic women with a singleton or twin gestation [5]

The combination of previous spontaneous preterm birth and a short cervix markedly increases the risk of recurrent spontaneous preterm birth. Indeed, among women with a previous spontaneous preterm birth, the risk of recurrent spontaneous preterm birth is about 3-fold higher in those with a cervical length $<25 \mathrm{~mm}$ than in those with a cervical length $>25 \mathrm{~mm}$ in the mid-trimester [6].

Vaginal progesterone administration and the placement of a cervical cerclage have been proposed for preventing preterm birth in patients with a singleton gestation, previous spontaneous preterm birth, and a sonographic short cervix [7]

The aim of present study was to compare the efficacy of vaginal progesterone and cerclage in preventing preterm birth.

\section{Patients and Methods}

This randomized prospective study was conducted at Kafr El Sheikh General Hospital during the period from May 2018 to September 2021.

A total 150 pregnant women at high risk of preterm birth who were chosen from the outpatient clinics. They all had singleton pregnancy with gestational age at the first antenatal visit of 12-16 weeks. Additionally, they had history of previous spontaneous preterm labor, and they all presented with sonographic cervical length $<25 \mathrm{~mm}$ in $\mathrm{mid}$ trimester.

Patients were divided into two groups: Group (A): 75 patients underwent vaginal cervical cerclage, and Group (B): 75 patients received 200mg $/ \mathrm{d}$ vaginal progesterone suppositories until the 37 th gestational week.

Treatment was started as started as soon as the participant was controlled in the trial and continued till labour. The treatment is considered successful if the pregnancy continued beyond 37 weeks of gestation.

Inclusion criteria: High-risk women for PTL with singleton pregnancy and at least one prior preterm birth before 34 weeks, who were found to have a short cervical length (cervical length $<25 \mathrm{~mm}$ ) detected on transvaginal ultrasound examination.
Exclusion criteria: Women with multiple gestations, underweight and obese women, history of failed previous cerclage, history of high risk pregnancy, and women with actual or threatened preterm labor, second trimester bleeding or premature rupture of membranes.

All women were subjected to:

A- At the first antenatal visit:

1- History taking.

2- Estimation of gestational age: Period of gestation was calculated with known last menstrual Period, and assessed by clinical examination and ultrasound. Patients general physical examination was done. Vitals signs were recorded. Cardiovascular system and respiratory system were examined.

3- Abdominal examination-uterine heights presentation position lie of the fetus liquor volume fetal heart rate were recorded. Uterine contractions were evaluated with respect to frequency and duration.

4- Determination of the baseline mean arterial blood pressure maternal heart rate pelvic examination and fetal heart rate assessment were done before the start of the treatment.

5- Laboratory investigations: Complete blood picture. Renal function tests liver function tests urine albumin fasting and postprandial blood sugar.

6- All women in the study were randomized to receive (Group A) or progesterone vaginal suppositories $200 \mathrm{mg}$ once daily at bed time (Group B) patients underwent vaginal cervical cerclage. Treatment was started as soon as the participant was enrolled in the study and continued beyond 37 weeks of gestation.

7- All the patients received dexamethasone $8 \mathrm{mg}$ intramuscularly 4 doses.

8- All women were advised about the benefit of the drug used and A Written approval of the study was taken from each woman A Schedule of next visits was given to each woman.

B- At the follow-up visits:

1- All pregnant women were submitted to uteraction monitoring by an external tocodynamomerer every other week for 60 minutes by an external monitor while women in left lateral position We determine the frequency of contractions. A Positive test was considered when there were four or more contractions per hour before the 
30 th week of gestation and from 30 weeks onward 6 or more contractions per hour.

2- All pregnant women were asked for symptoms of preterm labor like heaviness cramps abdominal colic's and sudden gush of fluid.

3- The response to treatment was assessed by the time after which cessation of pains and cervical changes occurred prolongation of gestation duration after which cases were delivered.

4- Thereafter the women were followed routinely in the antenatal care.

5- Seven ml of venous blood were collected from each subject after his consent by the use of disposable sterile Plastic syringe each sample was divided as follow: $1.8 \mathrm{~m} 1$ blood was collected into tube containing $0.2 \mathrm{~m} 1$ of fir sodium citrate solution $38 \mathrm{gm} / \mathrm{I}$ (1:9) for prothrombin time. $2 \mathrm{ml}$ blood was collected into EDTA tube for complete blood count using ERMA PCE$210 \mathrm{~N}$ cell counter. The remaining $3 \mathrm{ml}$ blood were collected into plain centrifuge tube and allowed to clot for half an hour then centrifuged for 15 minutes at 3000 r.p.m for separation of serum by means of a clean dry Pasteur pipette the serum was drawn into clean dry for liver functions blood urea serum creatinine and fasting blood glucose. The analysis of liver functions blood urea serum creatinine and fasting blood glucose were performed on Konelab Thermo Scientific (Thermo Scientific-Finland) autoanalyzer.

\section{Technique of cervical cerclage:}

A McDonald cerclage, is essentially a purse string stitch used to cinch the cervix shut; the cervix stitching involves a band of suture at the upper part of the cervix while the lower part has already started to efface. This cerclage is placed between 12 weeks and 16 weeks of pregnancy. The stitch is generally removed around the 37 th week of gestation.

\section{Statistical analysis:}

The collected data were coded, processed and analyzed using the SPSS (Statistical Package for Social Sciences) version 22 for Windows ${ }^{\circledR}$ (IBM SPSS Inc, Chicago, IL, USA). Data were tested for normal distribution using the Shapiro Walk test. Qualitative data were represented as frequencies and relative percentages. Chi square test $\left(\chi^{2}\right)$ to calculate difference between two or more groups of qualitative variables. Quantitative data were expressed as mean $\pm \mathrm{SD}$ (Standard deviation). Independent samples $t$-test was used to compare between two independent groups of normally distributed variables (parametric data). $p$-value $<0.05$ was considered significant.

\section{Results}

Table (1): Distribution of study population according to age and mean age of the studied groups.

\begin{tabular}{lccccccc}
\hline Age (years) & Group I & Group II & Total & $\begin{array}{c}p- \\
\text { value }\end{array}$ \\
\hline$<20$ & 3 & $4.0 \%$ & 4 & $5.3 \%$ & 7 & $4.7 \%$ & 0.899 \\
$20-30$ & 58 & $77.3 \%$ & 56 & $74.7 \%$ & 114 & $76.0 \%$ & \\
$>30$ & 14 & $18.7 \%$ & 15 & $20.0 \%$ & 29 & $19.3 \%$ & \\
\hline Total & 75 & $100 \%$ & 75 & $100 \%$ & 150 & $100 \%$ & \\
Mean \pm SD & $27.23 \pm$ & $26.62 \pm$ & $26.96 \pm$ & 0.374 \\
& 4.12 & 4.25 & 3.95 & \\
\hline
\end{tabular}

A total number of 150 patients were included in this study whose overall age range was from 20 to 30 years with a mean \pm SD was $26.96 \pm 3.65$ years. It was $27.23 \pm 4.12$ years in group (I) and $26.62 \pm 3.95$ years in group (II), $(p=0.374)$. Seven $(4.7 \%)$ patients were below 20 years of age, 119 $(76 \%)$ were in the age group of 20-30 years, and $29(19.3 \%)$ patients had their age above 30 years. There was no statistically significant difference among the two study groups with respect to the age of pregnant women $(p=0.919)$ (Table 1).

Table (2): Parity distribution among study groups.

\begin{tabular}{llllllll}
\hline Parity & Group I & Group II & Total & $\begin{array}{c}p- \\
\text { value }\end{array}$ \\
\hline Zero & 22 & $29.3 \%$ & 25 & $33.3 \%$ & 47 & $31.3 \%$ & 0.894 \\
Only 1 parity & 24 & $32.0 \%$ & 21 & $28.0 \%$ & 45 & $30.0 \%$ & \\
2 to 3 parity & 27 & $36.0 \%$ & 26 & $34.7 \%$ & 53 & $35.3 \%$ & \\
Over 3 birth & 2 & $2.7 \%$ & 3 & $4.0 \%$ & 5 & $3.3 \%$ & \\
\hline Total & 75 & $100 \%$ & 75 & $100 \%$ & 150 & $100 \%$ & \\
\hline
\end{tabular}

As regard parity in vaginal progesterone group, the number of parity was zero in $29 \%, 1$ in $32 \%$, $2-3$ in $36 \%$ and more than 3 in $2.7 \%$ of cases respectively, whereas in Cervical Cerclage group, the number of parity was zero in $33.3 \%$, one in $28 \%, 2-3$ in $34.7 \%$ and more than 3 in $4 \%$ of cases (Table 2).

Furthermore, $20(13.3 \%)$ women have had prior history of PPROM, 65 (43.2\%) were the cases who delivered Preterm previously, and 55 (34.25\%) had previous history of abortion. The present study showed that there was no statistically significant difference between the two studied groups regarding previous history of PPROM, preterm labour, or abortion $(p>0.05)$ (Table 3$)$. 
Table (3): Previous history of preterm pre-labor rupture of membranes (PPROM), Preterm labor, and abortion.

\begin{tabular}{|c|c|c|c|}
\hline & $\begin{array}{c}\text { Total } \\
(\mathrm{n}=150)\end{array}$ & $\begin{array}{c}\text { Group (I) } \\
\mathrm{N}=75\end{array}$ & $\begin{array}{c}\text { Group (II) } \\
\mathrm{N}=75\end{array}$ \\
\hline \multicolumn{4}{|c|}{ Previous preterm } \\
\hline \multicolumn{4}{|c|}{$\begin{array}{l}\text { rupture of membrane } \\
(P P R O M): \\
\text { No }\end{array}$} \\
\hline $\mathrm{N}$ & 130 & 66 & 64 \\
\hline$\%$ & $86.6 \%$ & $88 \%$ & $85.3 \%$ \\
\hline \multicolumn{4}{|l|}{ Yes } \\
\hline $\mathrm{N}$ & 20 & 9 & 11 \\
\hline$\%$ & $13.3 \%$ & $12 \%$ & $14.6 \%$ \\
\hline$p$-value & & 0.0 & \\
\hline \multicolumn{4}{|c|}{ Prior Preterm labour: } \\
\hline \multicolumn{4}{|c|}{ None } \\
\hline $\mathrm{N}$ & 85 & 43 & 42 \\
\hline$\%$ & $56.6 \%$ & $57.3 \%$ & $56 \%$ \\
\hline \multicolumn{4}{|l|}{$1-2$} \\
\hline $\mathrm{N}$ & 64 & 31 & 33 \\
\hline$\%$ & $42.6 \%$ & $41.3 \%$ & $44 \%$ \\
\hline \multicolumn{4}{|l|}{3} \\
\hline $\mathrm{N}$ & 1 & 1 & 0 \\
\hline$\%$ & $0.66 \%$ & $1.3 \%$ & $0 \%$ \\
\hline \multicolumn{2}{|l|}{$p$-value } & \multicolumn{2}{|c|}{0.630} \\
\hline \multicolumn{4}{|c|}{ History of abortion: } \\
\hline \multicolumn{4}{|c|}{ None } \\
\hline $\mathrm{N}$ & 95 & 48 & 47 \\
\hline$\%$ & $63.3 \%$ & $64 \%$ & $62.6 \%$ \\
\hline \multicolumn{4}{|l|}{$1-2$} \\
\hline $\mathrm{N}$ & 51 & 27 & 26 \\
\hline$\%$ & $34 \%$ & $36 \%$ & $34.6 \%$ \\
\hline \multicolumn{4}{|l|}{$3-4$} \\
\hline $\mathrm{N}$ & 4 & 0 & 2 \\
\hline$\%$ & $0.26 \%$ & $0 \%$ & $2.6 \%$ \\
\hline$p$-value & & 0.2 & \\
\hline
\end{tabular}

Table (4): Cervical length, birth weight and Gestational age at delivery distribution among study groups.

\begin{tabular}{|c|c|c|c|c|}
\hline & $\begin{array}{c}\text { Group I } \\
(\mathrm{n}=75)\end{array}$ & $\begin{array}{c}\text { Group II } \\
(\mathrm{n}=75)\end{array}$ & $\begin{array}{c}\text { Total } \\
(\mathrm{n}=150)\end{array}$ & $\begin{array}{c}p- \\
\text { value }\end{array}$ \\
\hline \multicolumn{5}{|l|}{ Cervical length: } \\
\hline \multirow[t]{2}{*}{ Mean \pm SD } & $22.52 \pm$ & $22.17 \pm$ & $22.39 \pm$ & 0.450 \\
\hline & 3.02 & 3.25 & 3.21 & \\
\hline \multicolumn{5}{|l|}{ Birth weight $(g)$ : } \\
\hline \multirow[t]{2}{*}{ Mean \pm SD } & $2179.5 \pm$ & $2314.6 \pm$ & $2237.6 \pm$ & 0.002 \\
\hline & 302.1 & 227.3 & 264.7 & \\
\hline \multirow{3}{*}{$\begin{array}{l}\text { Gestational age at } \\
\text { delivery (Weeks): } \\
\text { Mean } \pm \text { SD }\end{array}$} & & & $35.87 \pm$ & 0.239 \\
\hline & $35.68 \pm$ & $36.14 \pm$ & 2.54 & \\
\hline & 2.63 & 2.11 & & \\
\hline
\end{tabular}

In Vaginal Progesterone group, the mean cervical length was 22.52 \pm 3.02 , whereas in Cervical Cerclage group the mean cervical length was 22.17 \pm 3.25 . There was no statistically significant difference in the mean cervical length between the 2 groups $(p=0.450)$ but clinically no difference can be detected. The distribution of cervical length in each group. There was statistically significant difference between the both studied groups regarding mean birth weight as it was $2179.5 \pm 302.1$ in women who received vaginal progesterone compared to $2237.6 \pm 264.7$ in women who underwent cerclage; with $p$-value $=0.002$. In vaginal progesterone the mean gestational age was $(35.68 \pm 2.63$ weeks) while it was $(36.14 \pm 2.11$ weeks $)$ in those who underwent cerclage. The mean gestational age improved in the cerclage groups by about 3.92 days. The gestational age at delivery was higher in the cerclage group than that in the progesterone group, but without significant difference $(p=0.239)$ (Table 4).

Table (5): Mode of delivery.

\begin{tabular}{|c|c|c|c|c|}
\hline & Group I & Group II & Total & $\begin{array}{c}p- \\
\text { value }\end{array}$ \\
\hline \multicolumn{5}{|l|}{ Mode of delivery: } \\
\hline NVD & $28 \quad 37.3 \%$ & $2026.7 \%$ & $4832 \%$ & 0.161 \\
\hline $\mathrm{CS}$ & $47 \quad 62.7 \%$ & $55 \quad 73.3 \%$ & $10268 \%$ & \\
\hline
\end{tabular}

The majority of the women $68 \%(n=102)$ delivered by caesarean section (CS), while vaginal delivery was conducted in 48 (32\%) of women for the current pregnancy. The cerclage compared with vaginal progesterone treatment had significantly increased rates of cesarean delivery $(73.3 \%$ versus $62.7 \%$ ) but without statistically significance difference $(p=0.161)$ (Table 5).

Table (6): Morbidity and mortality of newly born babies.

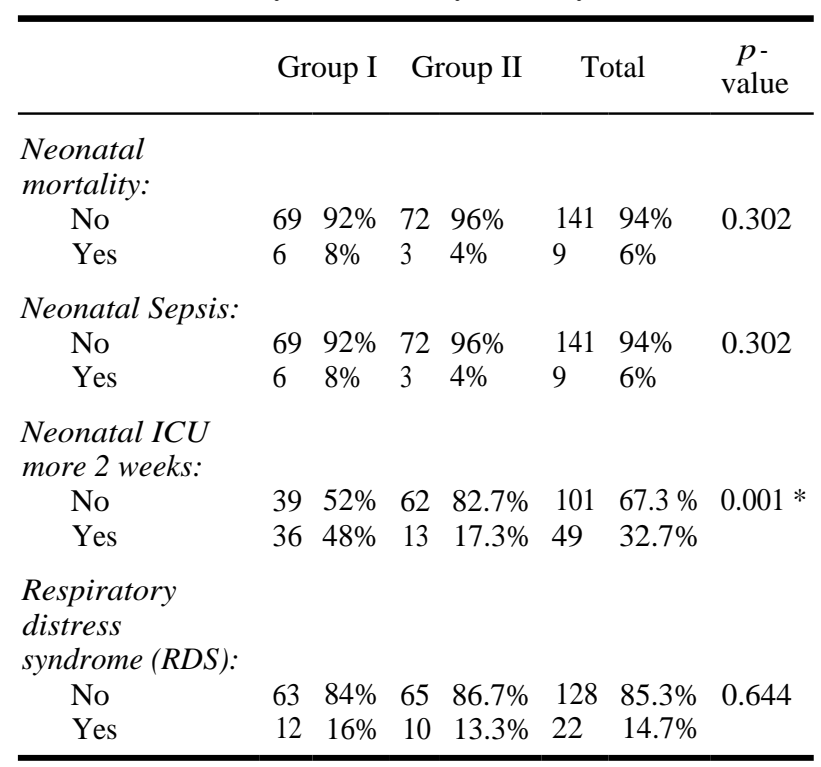

As regard neonatal outcome of the current delivery, the overall morbidity was shown in 22 cases $(19.8 \%)$ and mortality was $9(6 \%)$. Causes of mortality was low birth weight $(<2500 \mathrm{~g})$ in 5 
(4.5\%) babies; 3 of those five babies also had sepsis and the other $2(1.8 \%)$ had died due to lower gestational age of 30 week. Furthermore, the number of neonates admitted to the NICU was significantly lower in the cerclage group than that in the progesterone group $(p<0.001)$ (Table 6).

Table (7): Mean Apgar score in both studied groups.

\begin{tabular}{lcccc}
\hline $\begin{array}{l}\text { APGAR } \\
\text { score }(\mathrm{g})\end{array}$ & $\begin{array}{c}\text { Group I } \\
(\mathrm{n}=75)\end{array}$ & $\begin{array}{c}\text { Group II } \\
(\mathrm{n}=75)\end{array}$ & $\begin{array}{c}\text { Total } \\
(\mathrm{n}=150)\end{array}$ & $\begin{array}{c}p \text { - } \\
\text { value }\end{array}$ \\
\hline Mean $\pm \mathrm{SD}$ & $7.76 \pm 1.21$ & $7.81 \pm 1.32$ & $7.79 \pm 1.26$ & 0.809 \\
\hline
\end{tabular}

The mean Apgar score at 1 minute was higher in the cerclage group than that in the progesterone groups (7.79 vs. 7.72 ). This results showed that the difference in the mean Apgar score was not statistically significant between the progesterone and the cerclage groups $(p=0.809)$ (Table 7).

\section{Discussion}

An analysis of A total number of 150 patients were included in this study whose overall age range was from 20 to 30 years with a mean \pm SD was $26.96 \pm 3.65$ years. It was $27.23 \pm 4.12$ years in group (I) and $26.62 \pm 3.95$ years in group (II), $(p=0.374)$. Seven $(4.7 \%)$ patients were below 20 years of age, $119(76 \%)$ were in the age group of 20-30 years, and $29(19.3 \%)$ patients had their age above 30 years. There was no statistically significant difference among the two study groups with respect to the age of pregnant women $(p=0.919)$.

Di Renzo et al., [8] mentioned in their cohort study that preterm birth was mainly spontaneous in younger women (20-24 years) whereas it was more frequently of iatrogenic origin in women over 40 .

Another recent nationwide register-based cohort study in Finland found that the threshold-ages for preterm birth was 28 years (OR 1.10, 1.02-1.19) [9]. However the authors used different inclusion criteria and they did not stratify their results according to the onset of preterm birth (spontaneous or iatrogenic).

As regard parity, results of the current study revealed that about forty-seven $(31.3 \%)$ pregnant women were nullipara, $45(30 \%)$ pregnant women had only 1 parity, $53(35.3 \%)$ had 2 to 3 parity and remaining 5 pregnant women were multipara over 3. It was detected that there was no significant difference between both studied groups regarding parity $(p=0.894)$.
Chen et al., [10] found that parity was associated with preterm birth, with higher rates in nulliparous women and lower rates in multiparous women. The combined effects of advanced maternal age and parity have been reported.

Furthermore, in our study; 20 (13.3\%) women have had prior history of PPROM, 65 (43.2\%) were the cases who delivered Preterm previously, and $55(34.25 \%)$ had previous history of abortion. The present study showed that there was no statistically significant difference between the two studied groups regarding previous history of PPROM, preterm labour, or abortion $(p>0.05)$.

History of PPROM or prematurity was mentioned as risk factors of preterm birth as continued risk of recurrence support inflammatory processes with ongoing associated significant morbidity in the next pregnancy. Attempts have also been made to identify potential determinants of spontaneous preterm delivery and PPROM, highlighting differing responses in regulating inflammation and oxidative stress, and a potential mechanistic pathway involving overproduction of prostaglandin E2 and the protein connexion-43 in response to overextension of the amniotic membrane. Others have identified new candidate genes that may be related to the aetiology of PPROM [11,12]

Moreover, premature birth was also associated with subsequent premature births, i.e. a previous premature birth increases the risk of a second birth under the same condition and history of abortion have an important role in the risk of pre-term labor. However, prevalence of these factors may vary among different communities [13,14] .

In addition, Hosny et al., [15] reported that there was a statistically significant association between the presence of positive history of previous abortion and the risk of preterm birth. The same result was noted by Torchin and Ancel [16] in the EUROPOP study. They found that previous induced abortions were significantly associated with preterm birth and the risk of preterm birth increased with the number of abortions.

In addition, in our study the mean cervical length $(\mathrm{CL})$ of cases included in this study, CL was higher in cases who received vaginal progesterone $(22.52 \pm 3.2 \mathrm{~mm})$ compared to that of cases who underwent cerclage operation $(22.17 \pm$ $3.25 \mathrm{~mm}$ ). There was no difference between two studied groups regarding cervical length $(p=0.450)$.

A shortened cervical length has been used as one of the major risk factors for a preterm delivery. 
Identification of women with a short cervix and treatment with vaginal progesterone can reduce the frequency of preterm birth $[17,18]$.

Furthermore, the majority of the women $(68 \%$ $(\mathrm{n}=102)$ delivered by caesarean section (CS), while vaginal delivery was conducted in $48(32 \%)$ of women for the current pregnancy. The cerclage compared with vaginal progesterone treatment had significantly increased rates of cesarean delivery (73.3\% versus $62.7 \%$ ) but without statistically significance difference $(p=0.161)$.

Pang et al., [19] notified that the large range of cesarean delivery rates across hospitals suggests that practice variation, a modifiable factor, also played an important role in the increased prevalence of cesarean delivery.

In Egypt, one study reported that nearly $60 \%$ of population-based study of performed C-sections in 2014 that greatly exceeded the threshold of 10$15 \%$ recommended by WHO [20]

It was observed that in cases who received vaginal progesterone the mean gestational age was $(35.68 \pm 2.63$ weeks) while it was $(36.14 \pm 2.11$ weeks) in those who underwent cerclage. The mean gestational age improved in the cerclage groups by about 3.92 days. The gestational age at delivery was higher in the cerclage group than that in the progesterone group, but without significant difference $(p=0.239)$.

The results revealed that $6 \%$ of cases were delivered at gestational age from 28 to 32 weeks, $55.3 \%$ at more than 32 but less than 37 weeks, and the remaining $34 \%$ at more than 37 weeks of gestation. The current study showed that there was no significant difference between distribution of studied groups regarding gestational age at delivery $(p=0.803)$. Thus the number of cases that reached term was $72 \%$ in cases of vaginal progesterone only $\& 70.7 \%$ in cases of cerclage group.

Alsbjerg et al., [17] found that either vaginal progesterone only (68\% of cases reached term delivery) or cerclage (70\% of cases reached term delivery) only reduced the risk for preterm labor significantly compared to control. Moreover, combination of cerclage and vaginal progesterone resulted in higher reduction of preterm labor $(80 \%$ of cases reached term delivery).

Our results were similar to study done by Alfirevic et al., [21] as their results suggested similar effectiveness of currently available treatment strategies (vaginal progesterone and cerclage) for wom- en with singleton pregnancy who have at least one prior preterm birth and a shortened cervical length detected by transvaginal ultrasound examination.

In another study conducted by Conde-Agudelo et al., [22] women allocated to receive vaginal progesterone had significantly lower risk of preterm birth $<33$ weeks compared with those allocated to placebo/no treatment. In addition, vaginal progesterone was associated with a significant reduction in the risk of preterm birth $<35$ weeks' gestation, $<34$ weeks' <32 weeks' gestation, <30 weeks' gestation; moderate-quality evidence), and spontaneous preterm birth at $<33$ weeks' gestation.

Also, our results revealed that in the 2 of case $(1.8 \%)$ women with a lower gestational age of 2830 weeks at delivery, the neonatal morbidity was $2(100 \%) \&$ mortality was 2 (100) percent. In 9 $(8.1 \%)$ of cases whose gestational age was slightly better $30-32$ weeks morbidity was 4 (44.44\%) and mortality was $1(11.1 \%)$ percent. Further in case of $29(26.1 \%)$ women having gestational age 3235 week the morbidity was $6(20.7 \%)$ and mortality was $0(0 \%)$ percent. In addition, the percentage of morbidity and mortality among women with gestational age ranged from 35 to 37 weeks was $12.5 \%$ and 5\% respectively. After completion of 37 weeks, the morbidity rate was $(16.1 \%)$.

There was statistically significant difference between the both studied groups regarding mean birth weight as it was $2185.9 \pm 314.2$ in women who received vaginal progesterone compared to $2305.8 \pm$ 234.6 in women who underwent cerclage; with $p$ value $=0.025$ ) this may be due to higher percentage of term pregnancy in cerclage group than progesterone one. Also the mean Apgar score was not statistically significant between both groups ( $p=$ $0.808)$.

Romero et al., [23] pooled individual participant data from five studies, showed that vaginal progesterone significantly decreased the risk of preterm birth $\leq 34$ weeks of gestation or fetal death by $34 \%$, among women with a singleton gestation and a mid-trimester cervical length $(\mathrm{CL}) \leq 25 \mathrm{~mm}$. They found a benefit with vaginal progesterone on many outcomes.

In the meta-analysis of data from the OPPTIMUM study the reduction in preterm outcome was allied to a decrease in preterm birth $\leq 34$ weeks of gestation rather than fetal death because vaginal progesterone had no effect on the risk of this adverse outcome [24] 
Further research is required to explore vaginal progesterone's heterogeneity of results and to confirm the reduction in neonatal death with and randomly investigate combinations of both therapies.

An individual patient data (IPD) meta-analysis evaluated the efficacy of cerclage for the prevention of preterm birth and perinatal morbidity and mortality in asymptomatic women with a singleton gestation, previous spontaneous preterm birth, and a cervical length $<25 \mathrm{~mm}$ before 24 weeks of gestation. Cerclage, compared to no cerclage, significantly decreased the risk of preterm birth $<37$, $<35,<32$, and $<28$ weeks of gestation, composite perinatal morbidity and mortality, and birthweight $<1500 \mathrm{~g}[25]$

In Conde-Agudelo et al., [13] another IPD metaanalysis reported that vaginal progesterone administration to women with the same characteristics was associated with a significant reduction in the risk of preterm birth <32 weeks of gestation, composite perinatal morbidity and mortality, composite neonatal morbidity, and admission to the neonatal intensive care unit.

Regarding outcome, we found that either vaginal progesterone only or cerclage only reduced the risk for preterm labor significantly compared to placebo. Moreover, combination of cerclage and vaginal progesterone resulted in higher reduction of preterm labor. Our results were similar to Alfirevic et al., [21] as their results suggest similar effectiveness of currently available treatment strategies (vaginal progesterone and cerclage) for women with singleton pregnancy who have at least one prior preterm birth and a shortened cervical length detected by transvaginal ultrasound examination.

\section{Conclusion:}

Either vaginal progesterone or cervical cerclage had a significant beneficial effect in the protection against preterm delivery and improving perinatal outcomes among high risk women with a singleton gestation, previous spontaneous preterm birth or a midtrimester sonographic short cervix. The preventive effect of cerclage was slightly better than that of vaginal progesterone but progesterone had also assuring results.

\section{References}

1- CHEN X., ZHANG X., LI W., LI W., WANG Y., ZHANG S. and ZHU C.: Iatrogenic vs. Spontaneous Preterm Birth: A Retrospective Study of Neonatal Outcome Among Very Preterm Infants. Frontiers in Neurology, 12: 380, 2021.
2- ALGAMEEL A., ELHAWARY M., AMIN S. and ABD ELMENEM M.: Outcome of late preterm newborns in Upper Egypt. Egyptian Pediatric Association Gazette, 68 (1): 1-11, 2020.

3- BIGGIO J.R.: Current Approaches to Risk Assessment and Prevention of Preterm Birth-A Continuing Public Health Crisis. Ochsner Journal, 20 (4): 426-433, 2020.

4- ENAKPENE C.A., DIJEH F.C., VENGALIL E.T. and MASTROGIANNIS D.: An Overview Of The Role Of Cerclage In The Prevention Of Spontaneous Preterm Birth. Obstetrics Gynaecology \& Reproductive Medicine, 5 (3): 48-55, 2020.

5- NORMAN J.E.: Progesterone and preterm birth. International Journal of Gynecology \& Obstetrics, 150 (1): 24 30, 2020.

6- FACCHINETTI F., VERGANI P., DI TOMMASO M., MAROZIO L., ACAIA B., VICINI R. and D'AMICO R.: Progestogens for maintenance tocolysis in women with a short cervix: A randomized controlled trial. Obstetrics \& Gynecology, 130 (1): 64-70, 2017.

7- CAMPBELL S.: Prevention of spontaneous preterm birth: Universal cervical length assessment and vaginal progesterone in women with a short cervix: Time for action. American Journal of Obstetrics \& Gynecology, 218 (2): 151-158, 2018.

8- DI RENZO G.C., TOSTO V. and GIARDINA I.: The biological basis and prevention of preterm birth. Best Practice \& Research Clinical Obstetrics \& Gynaecology, 52: 13-22, 2018.

9- REHAL A., BENKÖ Z., MATALLANA C.D.P., SYNGELAKI A., JANGA D., CICERO S. and NICOLAIDES K.H.: Early vaginal progesterone versus placebo in twin pregnancies for the prevention of spontaneous preterm birth: a randomized, double-blind trial. American Journal of Obstetrics and Gynecology, 224 (1): 86-e1, 2021.

10- CHEN K.H., CHEN I.C., YANG Y.C. and CHEN K.T.: The trends and associated factors of preterm deliveries from 2001 to 2011 in Taiwan. Medicine, 98 (13): 1-10, 2019.

11- ALCÁNTARA-ALONSO V., PANETTA P., DE GORTARI P. and GRAMMATOPOULOS D.K.: Corticotropinreleasing hormone as the homeostatic rheostat of fetomaternal symbiosis and developmental programming in utero and neonatal life. Frontiers in Endocrinology, 8: 161-65, 2017.

12- BUEN M., AMARAL E., SOUZA R.T., PASSINI R., LAJOS G.J., TEDESCO R.P., NOMURA M.L., DIAS T.Z., REHDER P.M., SOUSA M.H. and CECATTI J.G.: Maternal Work and Spontaneous Preterm Birth: A Multicenter Observational Study in Brazil. Scientific Reports, 10 (1): 1-0, 2020.

13- CONDE-AGUDELO A., ROMERO R., NICOLAIDES K., CHAIWORAPONGSA T., O'BRIEN J.M., CETINGOZ E. and HASSAN S.S.: Vaginal progesterone vs cervical cerclage for the prevention of preterm birth in women with a sonographic short cervix, previous preterm birth, and singleton gestation: A systematic review and indirect comparison metaanalysis. American Journal of Obstetrics and Gynecology, 208 (1): 42-e1, 2013.

14- NISHIMURA F., MOGAMI H., MORIUCHI K., CHIGUSA Y., MANDAI M. and KONDOH E.: Mechanisms of 
thrombin-Induced myometrial contractions: Potential targets of progesterone. PloS One, 15 (5): 231944, 2020.

15- HOSNY A.E.D.M., FAKHRY M.N., EL-KHAYAT W. and KASHEF M.T.: Risk factors associated with preterm labor, with special emphasis on preterm premature rupture of membranes and severe preterm labor. Journal of the Chinese Medical Association, 83 (3): 280-287, 2020.

16- TORCHIN H. and ANCEL P.Y.: Epidemiology and risk factors of preterm birth. Journal De Gynecologie, Obstetrique Et Biologie De La Reproduction, 45 (10): 1213 1230,2016

17- ALSBJERG B., THOMSEN L., ELBAEK H.O., LAURSEN R., POVLSEN B.B., HAAHR T. and HUMAIDAN P.: Progesterone levels on pregnancy test day after hormone replacement therapy-cryopreserved embryo transfer cycles and related reproductive outcomes. Reproductive Biomedicine Online, 37 (5): 641-647, 2018.

18-AYUSO M., VAN CRUCHTEN S. and VAN GINNEKEN C.: Birthweight determines intestinal microvasculature development and alters endothelial nitric oxide synthase density in young piglets. Anatomia, Histologia, Embryologia, 49 (5): 627-634, 2020.

19- PANG, Q., JIA X. and CHEN L.: Perinatal outcomes after emergency cervical cerclage for cervical insufficiency with prolapsed membranes. Medical Science Monitor: International Medical Journal of Experimental and Clinical Research, 25: 4202, 2019.

20- AL RIFAI R.H.: Trend of caesarean deliveries in Egypt and its associated factors: Evidence from national surveys, 2005-2014. BMC Pregnancy and Childbirth, 17 (1): 114, 2017.
21- ALFIREVIC Z., OWEN J., CARRERAS MORATONAS E., SHARP A.N., SZYCHOWSKI J.M. and GOYA J.M.: Vaginal progesterone, cerclage or cervical pessary for preventing preterm birth in asymptomatic singleton pregnant women with a history of preterm birth and a sonographic short cervix. Ultrasound Obstet. Gynecol., 41: 146-151, 2013.

22- CONDE-AGUDELO A., ROMERO R., DA FONSECA E., O'BRIEN J.M., CETINGOZ E., CREASY G.W., HASSAN S.S., EREZ O., PACORA P. and NICOLAIDES K.H.: Vaginal progesterone is as effective as cervical cerclage to prevent preterm birth in women with a singleton gestation, previous spontaneous preterm birth, and a short cervix: Updated indirect comparison meta-analysis. American Journal of Obstetrics and Gynecology, 219 (1): 1025, 2018.

23- ROMERO R., YEO L., CHAEMSAITHONG P., CHAIWORAPONGSA T. and HASSAN S.S.: Progesterone to prevent spontaneous preterm birth. In Seminars in Fetal and Neonatal Medicine, 19: 15-26, 2014.

24- NORMAN J.E., MARLOW N., MESSOW C.M., SHENNAN A., BENNETT P.R. and THORNTON S.: Vaginal progesterone prophylaxis for preterm birth (the OPPTIMUM study): A multicentre, randomized, double-blind trial. Obstetrical \& Gynecological Survey, 71 (9): 517 518,2016

25- BERGHELLA V., RAFAEL T.J., SZYCHOWSKI J.M., RUST O.A. and OWEN J.: Cerclage for short cervix on ultrasonography in women with singleton gestations and previous preterm birth: A meta-analysis. Obstetrics \& Gynecology, 117 (3): 663-671, 2011. 


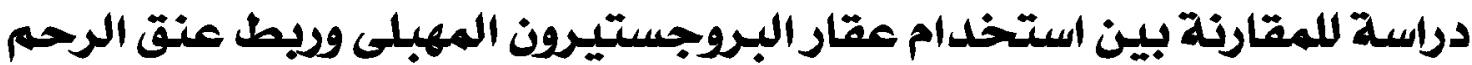

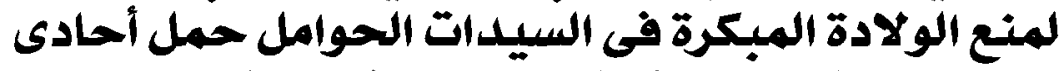

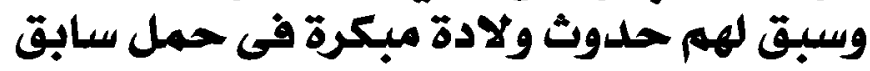

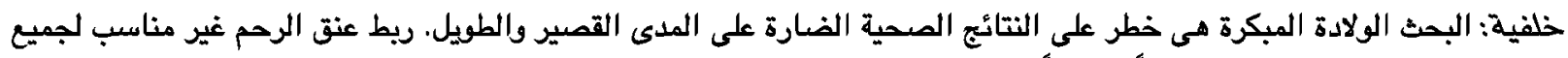

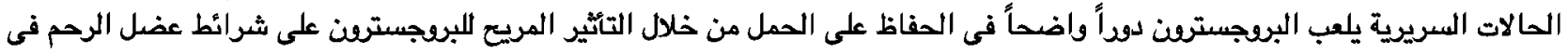

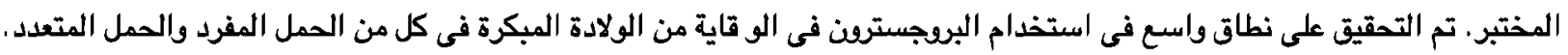

$$
\text { الهدف من الدراسة: هو مقارنة فعالية البروجسترون المهبلى وربط عنق الرحم منع الولادة المبكرة. }
$$

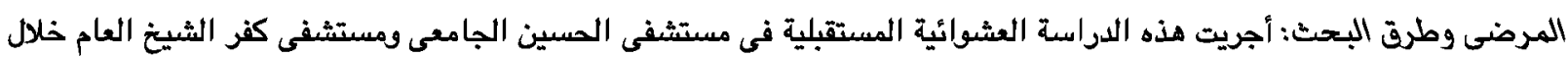

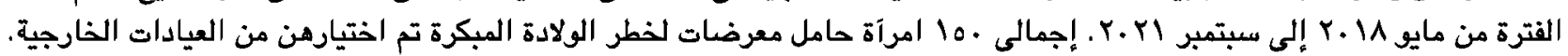

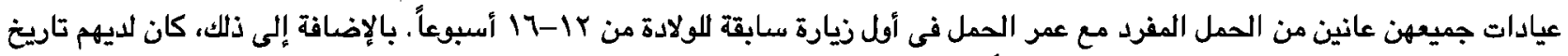

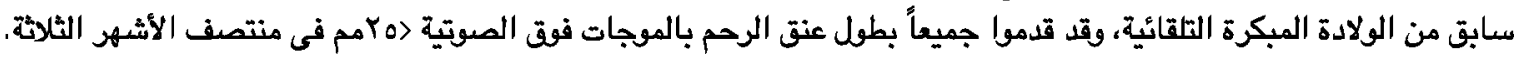

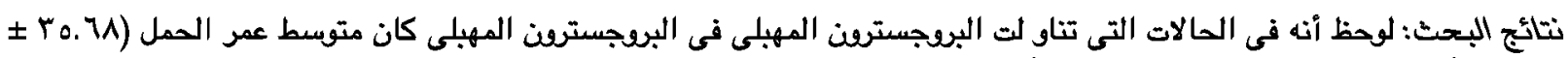

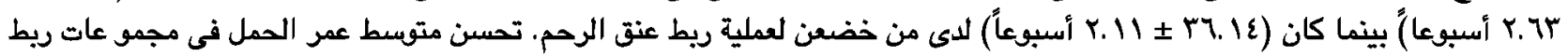

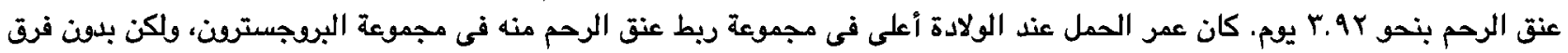

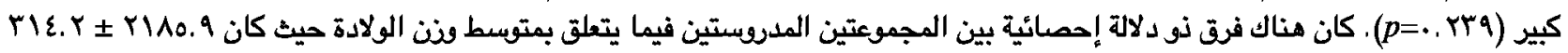

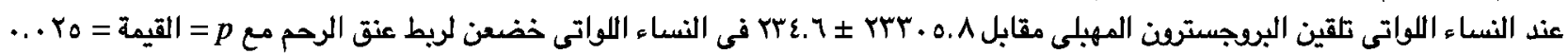

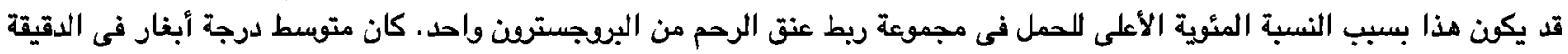

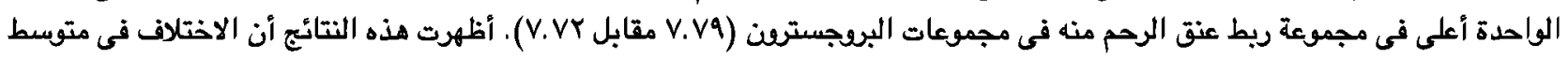

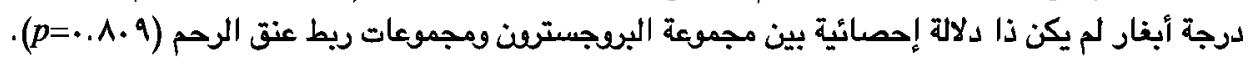

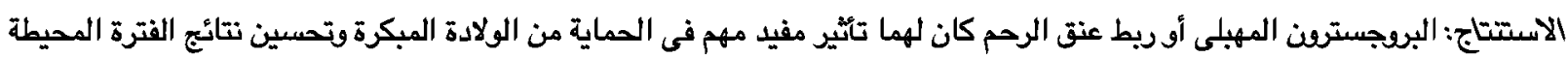

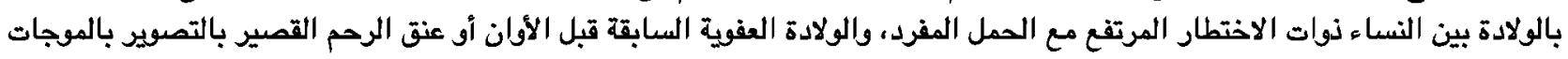
فوق الصوتية فى منتصف الفصل. 